\title{
PENGARUH DIMENSI GAMBAR PADA KLASIFIKASI MOTIF BATIK MENGGUNAKAN CONVOLUTIONAL NEURAL NETWORK
}

\author{
Rizki Mawan, Kusrini, Hanif Al Fatta \\ Program Studi Magister Teknik Informatika, Universitas Amikom Yogyakarta \\ Jl. Ring Road Utara, Condong Catur, Sleman, Yogyakarta \\ rizki.mawanestudents.amikom.ac.id, kusrini@amikom.ac.id, hanif.a@amikom.ac.id
}

\begin{abstract}
Indonesia is a country with many fascinating cultural assets. Batik is one of the most beautiful cultural assets that should be preserved. Batik existed with many motifs and styles and has been a significant cultural cloth for many regions spread along the Java island. This research proposed the computation for identifying three popular motifs and styles: megamendung, kawung, and parang. This research employed a Convolutional Neural Network classifier to identity those three popular batik motifs. This research used an image size of $64 \times 64,128 \times 128$, and $256 \times 256$ for the input images, and the influence of the size or dimension for these inputs have been analyzed. The final result showed that the highest accuracy is reached at $92.85 \%$ on epoch $=240$ and batch size $=5$
\end{abstract}

Keywords - Batik, Convolutional Neural Network, Accuracy, Dimension

\begin{abstract}
Abstrak - Banyak budaya di Indonesia yang masih menjadi kebanggan dan dijaga kelestarian nya. Salah satunya adalah batik. Jika berbicara tentang batik sekilas kita mengingat tentang berbagai macam motif yang dimiliki yang tersbar di Indonesia terutama di pulau Jawa. Pada penelitian kali ini motif batik yang diteliti adalah batik megamendung,batik kawung dan batik parang. Alasan pemilihan ketiga motif tersebut karena ketiga motif tersebut sangat diminati oleh khalayak ramai(Populer), dan ketiga motif tersebut memliki makna tersendiri yang sangat mewakili masyarakat Indonesia. Tujuan dari klasifikasi batik adalah untuk mengetahui keakuratan akurasi motif batik khusus nya motif batik kawung,megamendung, dan parang. Fokus pada penelitian ini adalah penggunaan dimensi gambar yang dapat mempengaruhi akurasi yang dihasilkan. Dimensi yang digunakan adalah $64 \times 64,128 \times 128$, dan 256x256. Akurasi yang dihasilkan dengan menggunakan metode Convolutional Neural Network yang paling tinggi yaitu $92,85 \%$ dengan menggunakan epoch $=240$ dan batch_size $=5$.
\end{abstract}

Kata Kunci - Batik, Convolutional Neural Network, Akurasi, Dimensi

\section{PENDAHULUAN}

Dimasa sekarang ini masih banyak masyarakat modern memakai baju yang bermotif batik. Batik merupakan ikon budaya dari Indonesia dan telah diakui oleh UNESCO pada 2 oktober 2009 [1]. Bagi orang Jawa, batik adalah kain tradisional yang integral dengan identitas budaya mereka [2]. Motif batik saat ini sangat banyak bahkan mencapai ratusan motif yang tersebar di nusantara. Daerah di nusantara memiliki ciri khas masing-masing bahkan juga ada yang memiliki filosofi tersendiri.

Tujuan dari klasifikasi batik adalah untuk mengetahui keakuratan akurasi motif batik khusus nya motif dari pulau jawa yang merupakan pasar produksi terbesar batik. Motif batik yang akan diteliti yaitu : Batik Parang (Solo,Jawa Tengah), Batik Megamendung (Cirebon,Jawa Barat), Batik Kawung (Yogyakarta). Alasan pemilihan ketiga motif tersebut karena ketiga motif tersebut sangat diminati oleh khalayak ramai(Populer), dan ketiga motif tersebut memliki makna tersendiri yang sangat mewakili masyarakat Indonesia . Kata "parang" berasal dari kata "pereng" yang berarti lereng, sehingga motifnya membentuk garis menurun secara diagonal. Kalau diperhatikan, garis ini membentuk huruf S yang saling menjalin tanpa terputus, yaitu menggambarkan kesinambungan dan semangat yang nggak pernah padam. Motif batik kawung berpola bulat-bulat seperti buah kawung yang menyerupai kelapa atau kolang-kaling. motif kawung menggambarkan bahwa manusia harus selalu membantu dan bermanfaat bagi orang lain. Selanjutnya adalah motif batik megamendung, berasal dari kata mega (awan/langit) dan mendung (saat sebelum turun hujan). Istilah mendung ini diartikan sebagai sifat yang sabar dan tidak mudah marah. Jadi, diharapkan orang yang memakai batik motif ini pun menjadi lebih sabar dan kalem.

Klasifikasi dapat digunakan pada beberapa bidang seperti machine learnin,deep learning dan artficial intelgence.Trend pada deep learning telah meningkat pada 10 tahun terakhir. Maka dari itu penggunaan klasifikasi pada deep learning diharapkan dapat menemukan akurasi/hasil yang tinggi.Proses klasifikasi tidak lepas dari data yang digunakan, baik berupa teks atau gambar(image processing). Namun,jika menggunakan image processing terdapat dimensi gambar. Menurut KBBI dimensi adalah ukuran yang meliputi panjang, luas, tinggi, lebar dan sebagainya. Maka dari itu perlu melakukan penelitian apakah dimensi berpengaruh pada proses klasifikasi.

Dari penjelasan diatas, maka peneliti mengambil judul penelitian"Pengaruh dimensi gambar pada klasifikasi motif batik menggunakan convolutional neural network". Hasil dari penelitian ini diharapkan 
dapat menjadi acuan penggunaan dimensi yang tepat pada gambar agar menghasilkan akurasi yang tinggi dan waktu komputasi tidak terlalu lama.

\section{A. Batik}

Batik adalah bentuk seni visual pada bahan tekstil yang diproduksi menggunakan teknik menggambar tradisional yang berasal dari Indonesia [3]. Batik memiliki berbagai macam motif. Pada penelitian ini motif batik yang ingin diteliti adalah motif parang,motif megamendung dan motif kawung.

Penelitian batik telah dilakukan oleh A. A. Kasim, R. Wardoyo, and A. Harjoko yang membahas tentang"Klasifikasi Batik menggunakan Artficial neural network berdasarkan fitur tekstur-bentuk ornamen utama". Motif batik yang diteliti adalah ceplok, grompol, gurda , kawung, mega mendung , parang dan sido asih. Tujuan penelitian ini adalah untuk membagi gambar batik berdasarkan kelas masingmasing pola sehingga dengan mudah dapat dikenali oleh fitur-fiturnya Hasil analisis pada penelitian ini adalah pelatihan dengan fitur bentuk dan pengujian dengan bentuk Fitur memiliki akurasi terendah 82,65\% (pelatihan) dan $80,95 \%$ (pengujian). Dengan menggabungkan fitur fitur tekstur dan bentuk dapat meningkatkan nilai akurasi menjadi 90,48\%.[4]

Penelitian sebelumnya A. Haris Rangkuti dkk, tujuan penelitian ini adalah Klasifikasi Batik menggunakan Content Based Batik Image Retrieval (CBBIR). Akurasi yang dihasilkan dari presisi optimal penggunaan CBBIR rata-rata pada 90-92\%[5]

\section{B. Deep Learning}

Deep Learning dapat memecahkan masalah sentral dalam pembelajaran representasi dengan memperkenalkan representasi yang diekspresikan dalam bentuk representasi lain yang lebih sederhana. Pembelajaran yang mendalam memungkinkan komputer untuk membangun konsep kompleks dari konsep yang lebih sederhana [6].

Penelitian deep learning telah dilakukan oleh Ira Zulfa dan Edi Winarko membahas tentang "Sentimen Analisis Tweet Berbahasa Indonesia dengan Deep Belief Network". Tujuan dari penelitian ini adalah untuk menentukan sentimen positif negatif dan netral untuk mengetahui akurasi model klasifikasi dengan menggunakan metode Deep Belief Network. Akurasi yang dihasilkan sebesar 93,31\%, Naive Bayes memiliki akurasi sebesar 79,10\%, dan SVM akurasi sebesar $92,18 \%$ [7]

\section{Convolutional Neural Network}

Sejauh ini penggunaan berbagi parameter yang paling populer dan luas terjadi dalam Convolutional neural network (CNN) yang diterapkan pada visi komputer. Gambar alami memiliki banyak sifat statistik yang tidak berbeda dengan terjemahan. Misalnya, foto kucing tetap menjadi foto kucing jika diterjemahkan satu piksel ke kanan. $\mathrm{CNN}$ mempertimbangkan properti ini dengan berbagai parameter di beberapa lokasi gambar[6]. Proses CNN diawali dengan konvlusi dan dimasukkan kedalam arsitektur yang telah ditentukan (layer,max_polling,flatten,dense) disesuaikan

Penelitian sebelumnya Yohanes Gultom, Rian Josua Masikome, Aniati Murni Arymurthy. Tujuan penelitian ini adalah Masalah Invariance dilemma menjadi tantangan pada penelitian batik, Convolutional Neural Network, CNN diharpakan mampu mengatasi masalah invariance dilema pada klasifikasi citra. Hasil dari penelitian ini adalah Pelatihan dengan fitur bentuk dan pengujian dengan fitur bentuk memiliki akurasi terendah yaitu $82,65 \%$ (pelatihan) dan $80,95 \%$ (pengujian) dan Dengan menggabungkan fitur fitur tekstur dan bentuk dapat meningkatkan nilai akurasi menjadi 90,48\% [8].

Penelitian sebelumnya A. Y. Wicaksono,dkk, tujuan penelitian ini adalah Modifikasi klasifikasi arsitektur batik menggunakan metode Convolutional Neural Network. Metode CNN yang diusulkan dengan arsitektur jaringan IncRes dapat digunakan untuk klasifikasi citra motif batik dengan akurasi 70,84\% [9].

Penelitian sebelumnya Abror, Tujuan dari penelitian ini adalah melakukan klasifikasi citra kebakaran menggunakan CNN. Citra dari kamera CCTV dijadikan sebagai dataset. CCTV digunakan untuk memantau terjadinya kebakaran pada suatu lokasi, Akurasi yang dihasilkan menggunakan model pada tahap pelatihan sebesar $98.8 \%$ dan pada tahap pengujian sebesar 90\%.[10].

\section{Dimensi}

Dimensi adalah ukuran yang mencakup panjang, lebar, tinggi dan sebaginya. Penelitian Dimensi telah dilakukan oleh Firda A. Ma'ruf dkk membahas tentang "Analisis Pengaruh Metode Reduksi Dimensi Minimum Redundancy Maximum Relevance pada Klasifikasi Kanker Berdasarkan Data Microarray Menggunakan Classifier Support Vector Machine”. Tujuan dari penelitian ini adalah melakukan klasifikasi dimana diagnosis pengklasifikasian apakah seseorang terkena suatu kanker atau tidak kanker atau jenis kanker yang kemungkinan diidap oleh orang tersebut. Hasil dari penelitian ini adalah 0.9657 atau $96.57 \%$ [11].

\section{METODE PENELITIAN}

Dalam penelitian ini peneliti menggunakan metode Kuantitatif. Metode penelitian kuantitatif merupakan suatu cara yang digunakan untuk menjawab masalah penelitian yang berkaitan dengan data berupa angka [12]. Jenis pengumpulan data pada penelitian ini yaitu Penelitian Eksperimen. Penelitian eksperimen (Experimental Research) adalah suatu penelitian yang berusaha mencari pengaruh variabel tertentu terhadap variabel lainya dalam kondisi yang terkontrol secara ketat. 
1. Study Literatur

Study literatur berfungsi untuk mengumpulkan informasi terkait dengan batik dan menentukan metode yang ingin digunakan dalam pada penelitian ini.

2. Pengumpulkan Data

Metode pengumpulan data yang peneliti lakukan untuk mendapatkan citra batik yaitu dengan cara mengambil/mendownload melalui google. Untuk mencari kecepatan klasifikasi dan akurasi data diambil dari github.com, https://fasnina.com, dan google images

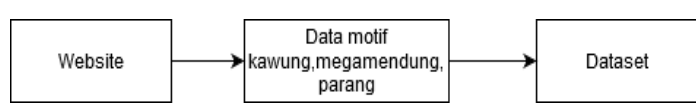

Gambar 1. Metode pengumpulan data

\section{Mengolah Data}

Pengolahan data diakukan dengan melakukan pengelompokan terhadap data kedalam class yang sudah ditentukan sehingga memudahkan peneliti dalam melakukan langkah selanjutnya

4. Pengamatan Metode

Tahapan berikutnya yaitu mempelajari metode yang dapat digunakan untuk membuat model dan melakukan prediksi.

5. Implementasikan Metode

Tahapan berikutnya yaitu mengimplementasikan data kedalam metode yang digunakan

Alur penelitian dapat dilihat pada gambar 2.

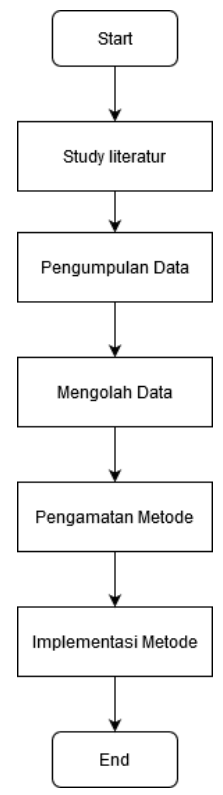

Gambar 2. Alur penelitian

\section{HASIL DAN PEMBAHASAN}

\section{Data}

Metode pengumpulan data yang peneliti lakukan untuk mendapatkan citra batik yaitu dengan cara mengambil/mendownload melalui google. Data yang digunakan memiliki ekstensi .jpg. Banyaknya data yang digunakan pada penelitian ini adalah 120 gambar terbagi atas 3 motif yang telah dipisah. Data tersebut dilakukan pembagian 80:20. Dimana 100 sebagai uji dan 20 sebagai pelatihan. Tabel 1 menunjukkan motif batik yang diteliti.

\begin{tabular}{|l|l|l|}
\multicolumn{3}{|c}{ Tabel 1. Motif batik } \\
\hline No & Motif Batik & Jumlah \\
\hline 1 & Batik Megamendung & 40 \\
\hline 2 & Batik Kawung & 40 \\
\hline 3 & Batik Parang & 40 \\
\hline
\end{tabular}

Dari ketiga motif tersebut akan memiliki class masing-masing namun jumlah datanya tetap sama di setiap class yaitu 40 class. Gambar pada setiap class memiliki ukuran/dimensi original $120 \times 120$, namun pada penelitian ini gambar akan diubah dimensi nya untuk mencari akurasi terbaik yang bisa dihasilkan ,menjadi pembanding dan menjadi pertimbangan. Penggunaan dimensi juga mempengaruhi waktu komputasi. Dimensi yang digunakan dapat dilihat pada tabel 2.

Tabel 2. Dimensi yang digunakan

\begin{tabular}{|l|l|}
\hline No & Dimensi/Ukuran \\
\hline 1 & $64 \times 64$ \\
\hline 2 & $128 \times 128$ \\
\hline 3 & $256 \times 256$ \\
\hline
\end{tabular}

Gambar batik yang ada telah diproses dan dimasukkan kedalam sub_plots. Motif batik yang diteliti dapat dilihat pada gambar 3 .

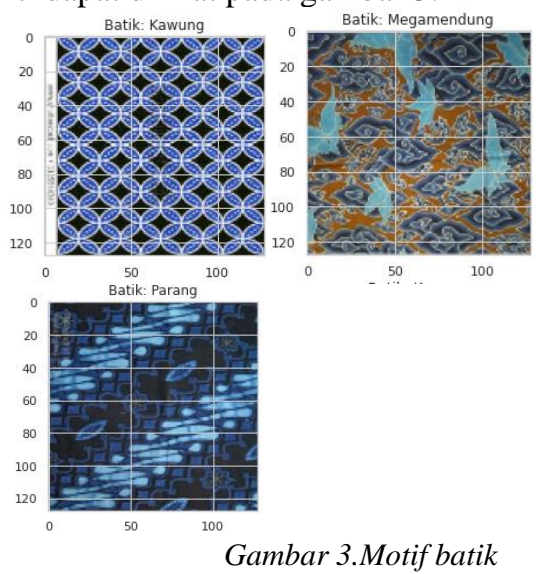

2. Convolutional Neural Network (CNN)

Setelah data diubah menjadi dimensi yang telah ditentukan maka selanjutnya memasukkan kedalam arsitektur/model CNN yang telah ditentukan. 


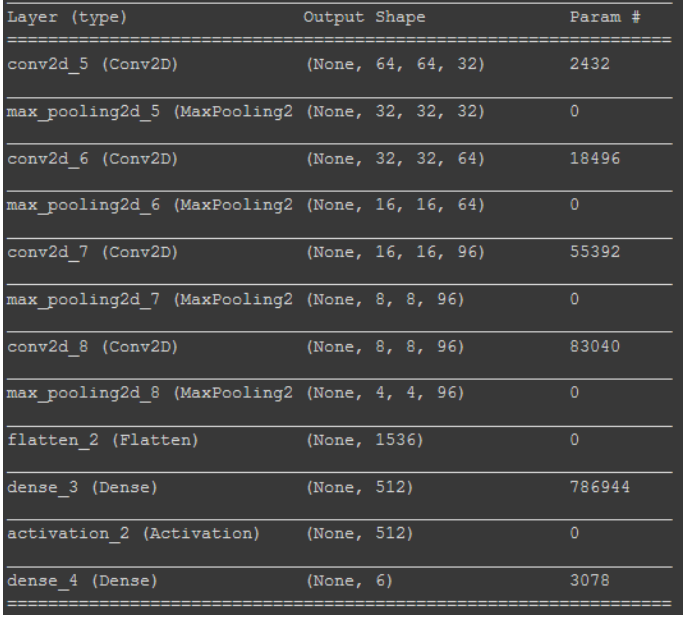

Gambar 4. Arsitektur CNN $64 x 64$

Arsitektur CNN dapat dilihat pada gambar 4 .Arsitektur CNN pada lapisan Input, data yang digunakan adalah data training. Kemudian data input diproses pada lapisan konvlusi menggunakan max_polling dan fungsi ReLU. Output pada lapisan konvlusi pertama dijadikan sebgai input pada proses konvlusi kedua, begitu juga seterusnya. Hasil dari proses konvlusi akan di kumpulkan dan diproses pada lapisan Flatten(fully connected). Berdasarkan model CNN pada gambar 3 dimana epoch 240, akurasi terbaik berurutan yang dihasilkan menggunakan data testing adalah $92,85 \%, 85 \%$ dan $80 \%$.Pemrograman tersebut dengan menggunakan Python dan software Google Collabs beserta library yang dibutuhkan.

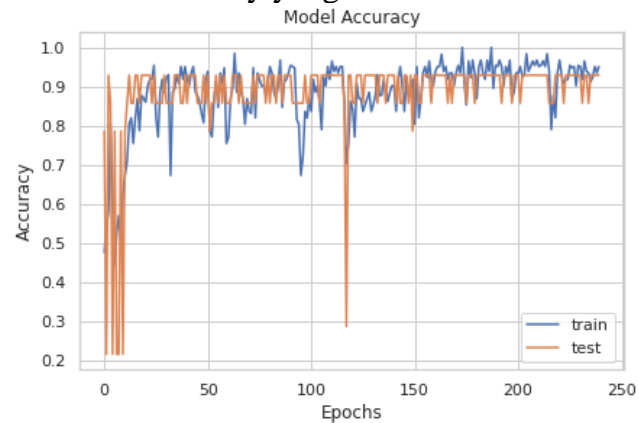

Gambar 5. Model Accuracy $64 x 64$

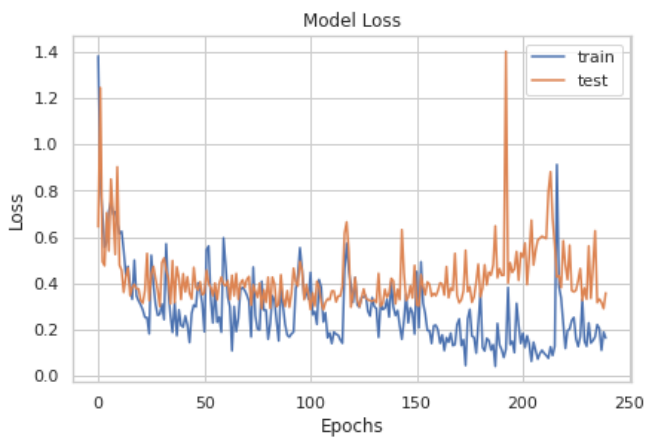

Gambar 6. Model Loss $64 x 64$

Pada gambar 5 merupakan hasil akurasi yang didapat mengunakan dimensi 64x64. Akurasi yang dihasilkan yaitu 92,85\% dengan 240 epochs. Pada gambar 6 dapat dilihat model loss yang dihasilkan pada data pelatihan dan data uji mengalami penurunan walaupun pada grafik tidak konstan naik dan turun. Namun model loss mengalami penurunan dan model accuracy mengalami peningkatan.

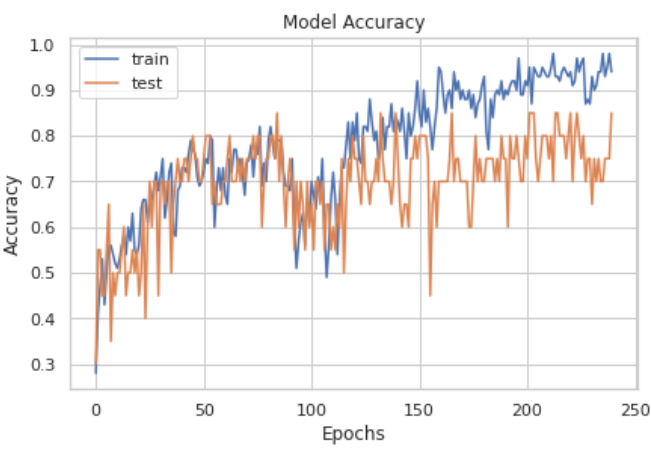

Gambar 7. Model Accuracy $128 \times 128$

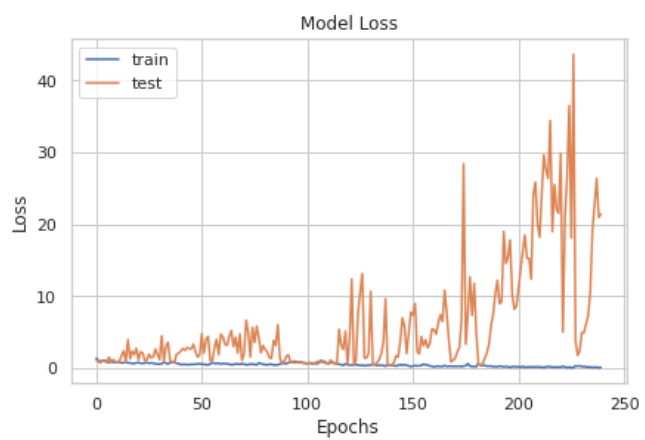

Gambar 8. Model Loss $128 \times 128$

Pada gambar 7 merupakan hasil akurasi yang didapat mengunakan dimensi $128 \times 128$. Akurasi yang dihasilkan yaitu $85 \%$ dengan 240 epochs. Pada gambar 8 dapat dilihat model loss yang dihasilkan data pelatihan dan data uji mengalami penaikan pada test dan penurunan pada data train, walaupun pada grafik tidak konstan naik dan turun. Namun model loss mengalami penurunan dan model accuracy mengalami peningkatan.

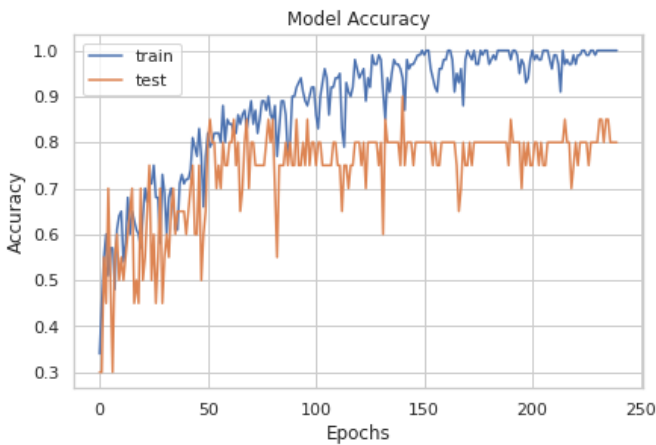

Gambar 9. Model Accuracy 256x256 


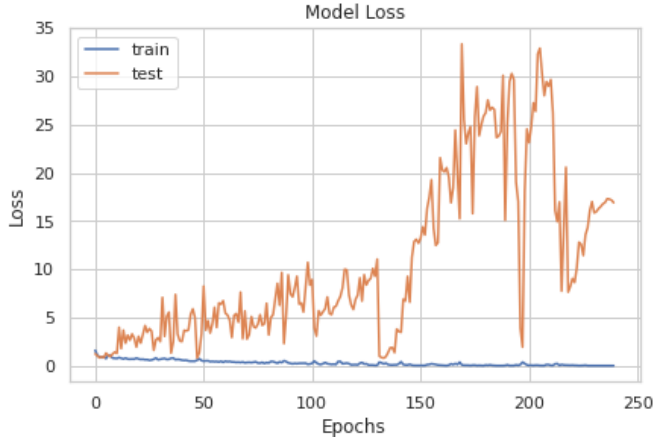

Gambar 10.Model Loss 256x256

Pada gambar 9 merupakan hasil akurasi yang didapat mengunakan dimensi 256x256. Akurasi yang dihasilkan yaitu $80 \%$ dengan 240 epochs. Pada gambar 10 dapat dilihat model loss yang dihasilkan pada data pelatihan dan data uji mengalami mengalami penaikan walaupun pada grafik tidak konstan naik dan turun. Namun model loss mengalami penurunan dan model accuracy mengalami peningkatan.

Dari ketiga hasil uji coba tersebut rata-rata akurasi yang dihasilkan diatas $85 \%$. Hal ini menunjukkan bahwa dimensi yang dipakai mempengaruhi akurasi yang dihasilkan. Detail akurasi dapat dilihat pada table 3

Table 3. Akurasi yang didapat

\begin{tabular}{|l|l|l|}
\hline No & Dimensi & Akurasi \\
\hline 1 & $64 \times 64$ & $92,85 \%$ \\
\hline 2 & $128 \times 128$ & $85 \%$ \\
\hline 3 & $256 \times 256$ & $80 \%$ \\
\hline \multicolumn{2}{|l|}{ Total } & $85,95 \%$ \\
\hline
\end{tabular}

\section{KESIMPULAN}

Berdasarkan penelitian dan implementasi pada ukuran gambar yang telah ditentukan, dapat diambil kesimpulan sebagai berikut :

1. Metode CNN dapat melakukan proses klasifikasi dengan baik

2. Pada penggunaan Convolutional Neural Network ukuran gambar mempengaruhi akurasi yang dihasilkan.

3. Akurasi yang dihasilkan Metode Convolutional Neural Network dengan ukuran $64 \times 64=92.85 \%$, $128 \times 128=85 \%, 256 \times 256=80 \%$.

\section{SARAN}

Penelitian yang dilakukan saat ini menggunakan total 120 dataset. Untuk penelitian selanjutnya dapat menggunakan lebih banyak dataset agar dapat mencapai akurasi yang maksimal

\section{DAFTAR PUSTAKA}

[1] E. Steelyana, "Batik, A Beautiful Cultural Heritage that Preserve Culture and Supporteconomic Development in Indonesia," Binus Bus. Rev., vol. 3, no. 1, p. 116, 2012, doi: 10.21512/bbr.v3i1.1288.

[2] C. Tresnadi and A. Sachari, "Identification of Values of Ornaments in Indonesian Batik in Visual Content of Nitiki Game," J. Arts Humanit., vol. 4, no. 8, pp. 25-39, 2015, doi: 10.18533/journal.v4i8.797.

[3] Y. Y. Sunarya, "Batik dalam Konteks Desain dan Kreatifitas Kini Master Sertifikasi Batik (Pembatik) View project Study of the development of textile fiber characteristics in undergarment View project," no. October 2013, 2016, doi: 10.13140/RG.2.1.2182.9366.

[4] A. A. Kasim, R. Wardoyo, and A. Harjoko, "Batik classification with artificial neural network based ontexture-shape feature of main ornament," Int. J. Intell. Syst. Appl., vol. 9, no. 6, pp. 55-65, 2017, doi: 10.5815/ijisa.2017.06.06.

[5] A. Haris Rangkuti, A. Harjoko, and A. E. Putro, "Content based batik image retrieval," $J$. Comput. Sci., vol. 10, no. 6, pp. 925-934, 2014, doi: 10.3844/jcssp.2014.925-934.

[6] A. Bengio, Yoshua, Goodfellow.ian, Courville, "Deep learning," Nature, vol. 29, no. 7553, pp. 1-73, 2015.

[7] I. Zulfa and E. Winarko, "Sentimen Analisis Tweet Berbahasa Indonesia Dengan Deep Belief Network," IJCCS (Indonesian J. Comput. Cybern. Syst., vol. 11, no. 2, p. 187, 2017, doi: 10.22146/ijccs.24716.

[8] Y. Gultom, A. M. Arymurthy, and R. J. Masikome, "Batik Classification using Deep Convolutional Network Transfer Learning," J. Ilmu Komput. dan Inf., vol. 11, no. 2, p. 59, 2018, doi: 10.21609/jiki.v11i2.507.

[9] A. Y. Wicaksono, N. Suciati, C. Fatichah, K. Uchimura, and G. Koutaki, "Modified Convolutional Neural Network Architecture for Batik Motif Image Classification," IPTEK J. Sci., vol. 2, no. 2, pp. 26-30, 2017, doi: 10.12962/j23378530.v2i2.a2846.

[10] Z. F. Abror, "Klasifikasi Citra Kebakaran Dan Non Kebakaran," vol. 24, no. 100, pp. 102-113.

[11] F. A. Ma and U. N. Wisesty, "Analisis Pengaruh Metode Reduksi Dimensi Minimum Redundancy Maximum Relevance pada Klasifikasi Kanker Berdasarkan Data 
Microarray Menggunakan Classifier Support Vector Machine Analysis of The Influence of Minimum Redundancy Maximum Relevance as Dimensiona," vol. 5, no. 1, pp. 1499-1506, 2018.

[12] M. P. Dr.Wahidmurni, "Pemaparan Metode Penelitian Kuantitatif,” pp. 1-16, 2017. 